\title{
INFLUÊNCIA DO CONTROLE DO PH NA MODULAÇÃO E OTIMIZAÇÃO DO MEIO DE CULTURA PARA A PRODUÇÃO DE GLICOHIDROLASES POR FUNGOS FILAMENTOSOS
}

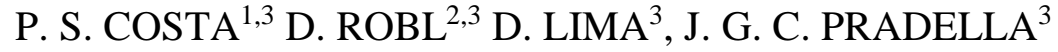 \\ ${ }^{1}$ Universidade Estadual de Campinas, Departamento de Engenharia Química \\ ${ }^{2}$ Universidade de São Paulo, Programa de Pós Gradução Interunidades em Biotecnologia \\ ${ }^{3}$ Centro de Pesquisa em Energia e Materiais/Laboratório Nacional de Ciência e Tecnologia do \\ Bioetanol - CTBE
}

E-mail para contato: patríciacosta.ufv@gmail.com

RESUMO - O melhoramento de meio de cultura por metodologias estatísticas é de grande interesse para a confecção de meios ótimos de produção das glicohidrolases, por fungos filamentosos. A execução de tais metodologias em reatores de bancadas com pH controlado é de elevada dificuldade, pois necessita de uma grande quantidade de reatores operando em conjunto, o que dificulta a realização de tais metodologias. O objetivo deste trabalho foi verificar a utilização do tampão phitalato de potássio para o controle do $\mathrm{pH}$, objetivando a possibilidade de realização do melhoramento do meio de cultura, em pequena escala, para os fungos filamentosos Penicillium echinulatim PS1M29 e Trichoderma harzianum linhagem P49P11. Os resultados demonstraram que a utilização do tamponamento do meio permite um considerável controle do $\mathrm{pH}$ diminuindo o desvio padrão dentro das triplicatas dos experimentos permitindo maior confiabilidade dos resultados de atividade enzimática das glicohidroláses. Este trabalho pode contribuir para auxiliar outros trabalhos de melhoramentos de meios de cultura para fungos filamentosos.

\section{INTRODUÇÃO}

Dentre as diversas etapas do processo de produção do etanol de segunda geração o maior gargalo está na etapa de hidrólise enzimática, que devido a baixa produção das glicohidrolases pelos microrganismos torna o processo inviável atualmente. Assim, estratégias para aumentar a produção/atividades dessas enzimas, necessárias para o processo de hidrólise da biomassa, são de grande interesse na comunidade científica e industrial.

Como os componentes do meio de cultura influenciam drasticamente no $\mathrm{pH}$, e o $\mathrm{pH}$ pode influenciar na síntese e na atividade enzimática das glicohidrolases, a exemplo do que ocorre com $T$. reesei (Tangnu et al. 1981, Sternberg et al. 1979). Em trabalhos de estudos de diferentes tipos de tampões realizados por Domingues et al (2000), foi demonstrado que o tampão biftalato de potássio era adequado para o cultivo de $T$. reesei. 


\section{9 a 22 de outubro de 2014 \\ Florianópolis/SC}

O uso de planejamentos estatísticos para a otimização de meios de cultura para a produção das glicohidrólases é uma estratégia promissora para incrementar a indução de tais enzimas, entretanto a necessidade de um rigoroso controle do $\mathrm{pH}$ ao longo do cultivo torna a utilização eficiente desta metodologia limitada pela necessidade de um grande numero de biorreatores em um mesmo bloco de experimentos.

Com base no estudo de Domingues et al (2000) e na necessidade de acessar um tampão eficiente para o controle do $\mathrm{pH}$ de cultivos de meios a serem otimizados foi escolhido o tampão ftalato de potássio $0,1 \mathrm{M} \mathrm{em} \mathrm{pH} 5$ para o presente estudo de modo a determinar a influencia do controle do pH pelo tampão ftalato de potássio no cultivo dos fungos filamentosos Penicillium echinulatim PS1M29 e Trichoderma harzianum P49P11 para aplicação da utilização do mesmo como controlador do $\mathrm{pH}$ em experimentos de otimização e modulação de meio de cultura.

A utilização de um tampão eficiente no controle do $\mathrm{pH}$ em meios de culturas que variam grandemente o $\mathrm{pH}$ ao longo do cultivo é de grande relevância pois permite que sejam realizados estudos de grandes quantidades de variáveis em planejamentos estatísticos utilizando apenas um bloco e dispensando o uso de biorreatores, com controle de $\mathrm{pH}$, nas etapas iniciais de screening, estudo e otimizações dos processos.

\section{Materiais e Métodos}

\subsection{Efeito do tampão sobre a variação do $\mathrm{pH}$ ao longo do cultivo e na atividade das glicohidrolases para fungos filamentosos}

Os experimentos de fermentação submersas foram conduzidos em shaker utilizando frascos de $500 \mathrm{~mL}$ contendo $200 \mathrm{~mL}$ dos diferentes meios de culturas testados por esse trabalho em uma temperatura de $29^{\circ} \mathrm{C}$ a $200 \mathrm{rpm}$ em pH 5,0 controlado com tampão biftalato de potássio. Alíquotas de $5 \mathrm{~mL}$ foram coletados em diferentes tempos, centrifugadas $\left(10000 \mathrm{rpm}, 10^{\circ} \mathrm{C}, 15\right.$ minutos) e o sobrenadante foi reservado para aferição do $\mathrm{pH}$ e posteriores análises das atividades enzimáticas contra o substrato papel de filtro.

\section{- Para o fungo filamentoso Penicillium echinulatim PS1M29}

Para o fungo filamentoso Penicillium echinulatim PS1M29 foi verificado a influência do tampão na atividade Fpase em cultivos de fermentação submersa contendo bagaços de cana-de-açucar submetidos a diferentes pré-tratamentos (explosão a vapor (BEX), explosão a vapor seguido de deslignificação (BED), tratamento hidrotérmico (BH), tratamento hidrotérmico e moído (BHM)) e com celulose comercial cellufloc (CEL). Esses experimentos foram realizados na presença e na ausência do tampão.

\section{- Para o fungo Filamentoso Trichoderma harzianum linhagem P49P11}

Para o fungo filamentoso Trichoderma harzianum linhagem P49P11 foi verificado a influência do tampão na atividade Fpase em cultivos de fermentação submersa contendo o meio otimizado por 
Delabona et al 2013 na presença e ausência do tampão.

2.2 Aplicação do controle do $\mathrm{pH}$ pelo tampão ftalato de potássio em experimentos de otimização/modulação de meio de cultura

\section{- Para o fungo filamentoso Penicillium echinulatim PS1M29 $\rightarrow$ modulação do meio}

A aplicação do tampão para controle do $\mathrm{pH}$ em experimentos de planejamentos estatísticos foi utilizado para a avaliação da influencia de 5 fatores no meio de cultura, aplicando a metodologia de planejamentos de experimento fracionado sendo as variações e os componentes demonstrado na Tabela 1. Amostras foram retiradas nos tempos de 96 e 144 horas e o $\mathrm{pH}$ foi aferido.

Tabela 1: Variáveis codificadas para PFF $2^{5-1}$ visando verificação da influência de componentes do meio de cultura na atividade de glicohidrolases para $P$. echinulatum

\begin{tabular}{|l|c|c|c|}
\hline Variáveis & $\mathbf{- 1}$ & $\mathbf{0}$ & $\mathbf{+ 1}$ \\
\hline Farelo de Soja (g/L) & 0 & 2,5 & 5 \\
\hline Farelo de Trigo (g/L) & 0 & 5 & 10 \\
\hline Sacarose (g/L) & 0 & 5 & 10 \\
\hline Extrato de Leveduras (g/L) & 0 & 1 & 2 \\
\hline Sol. sais (mL/L) & 50 & 175 & 300 \\
\hline
\end{tabular}

- Para o fungo Filamentoso Trichoderma harzianum linhagem P49P11 $\rightarrow$ otimização do meio

Foi validado também, a aplicação do controle do pH para a otimização de meios de cultura em dois planejamentos completos do tipo composto central rotacional para o fungo filamentoso $T$. harzianum cujos componentes avaliados estão apresentados na Tabela 2. Amostras foram retiradas nos tempos de 72 e 96 horas de cultivo e o $\mathrm{pH}$ foi aferido.

Tabela 2. Variáveis utilizadas no DCCR visando otimização da atividade de FPase para $T$. harzianum.

\section{Variáveis}

Pontos Axiais 


$$
-1,68\left(-2^{3 / 4}\right) \quad+1,68\left(+2^{3 / 4}\right)
$$

\begin{tabular}{ccc}
\hline Sacarose $(\mathrm{g} / \mathrm{L})$ & 0 & 10 \\
\hline Celulose $(\mathrm{g} / \mathrm{L})$ & 0 & 20 \\
\hline $\begin{array}{c}\text { Farelo de Soja }(\mathrm{g} / \mathrm{L}) \\
\text { Farelo de trigo }(\mathrm{g} / \mathrm{L})\end{array}$ & 0 & 15 \\
\hline
\end{tabular}

\section{RESULTADOS E DISCULSSÃO}

\subsection{Efeito do tampão sobre a variação do pH ao longo do cultivo e na atividade das glicohidroláses}

\section{- Para o fungo filamentoso Penicillium echinulatim PS1M29}

A Figura 1 mostra a atividade de Fpase em diferentes tempos de cultivo nos diferentes meios na presença e na ausência do controle de $\mathrm{pH}$ pelo tampão ftalato de potássio. Como pode ser observado o controle de $\mathrm{pH}$ para a atividade de Fpase nos diferentes meios de cultivos contribuiu para a diminuição do desvio padrão entre as triplicatas e padronizou a atividade de Fpase para os diferentes meios, mostrando que as diferenças nas atividades de Fpase não são devido a fonte de celulose ou ao pre-tratamento imposto no bagaço e sim pelas variações dos pHs ao longo do cultivo nos diferentes materiais. Com isso pode-se afirmar que para um cultivo utilizando $10 \mathrm{~g} / \mathrm{L}$ das fontes de celuloses utilizadas nesse trabalho para Penicillium echinulatim PS1M29 a indução de Fpase é a mesma e que o tampão biftalato de potássio não influencia negativamente na indução.

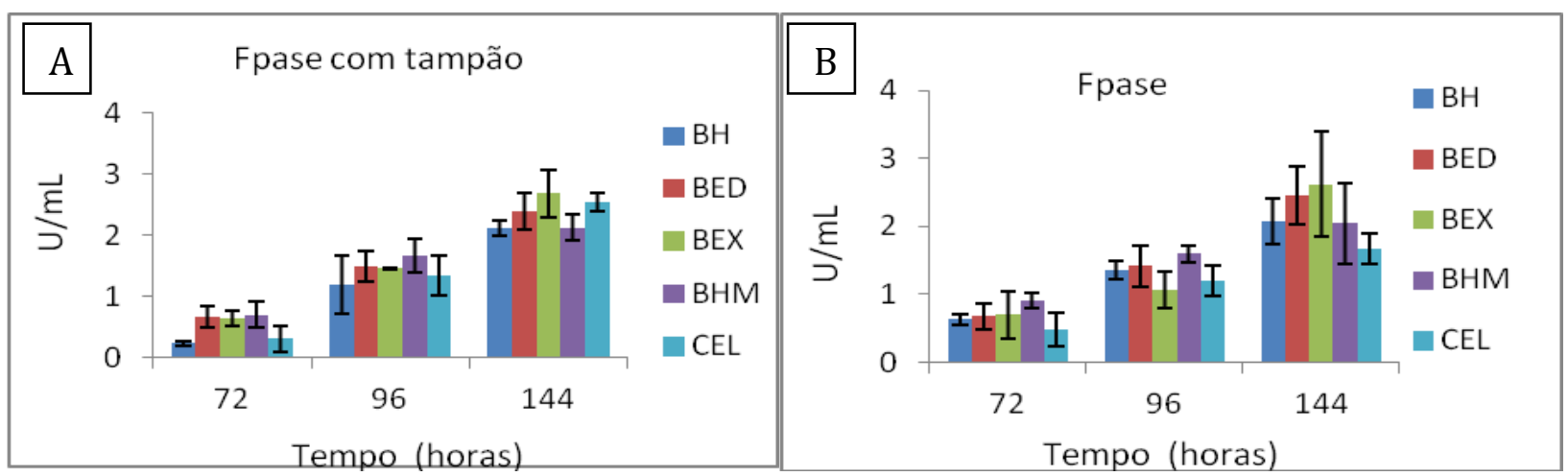

Figura 1: Cinética da produção de Fpase pelo fungo $P$. echinulatum S01M29 em fermentação submersa com as diferentes fontes de carbonos. Média das triplicatas com seu respectivo desvio 
padrão. A) Com pH 5,9 controlado pelo tampão biftalato de potássio 0,1M. B) pH livre, sem nem um controle.

A Figura 2 mostra a eficiência de tamponamento do tampão biftalato de potássio em $\mathrm{pH}$ 5,9 nos diferentes meios de cultura ao longo de todo o tempo do cultivo. Este resultado valida o uso desse tampão para o controle do $\mathrm{pH}$ ao longo do cultivo de Penicillium echinulatim PS1M29 visando estudos de meios de cultura que ocorre grande variação no $\mathrm{pH}$ para otimização das atividades das glicohidroláses.
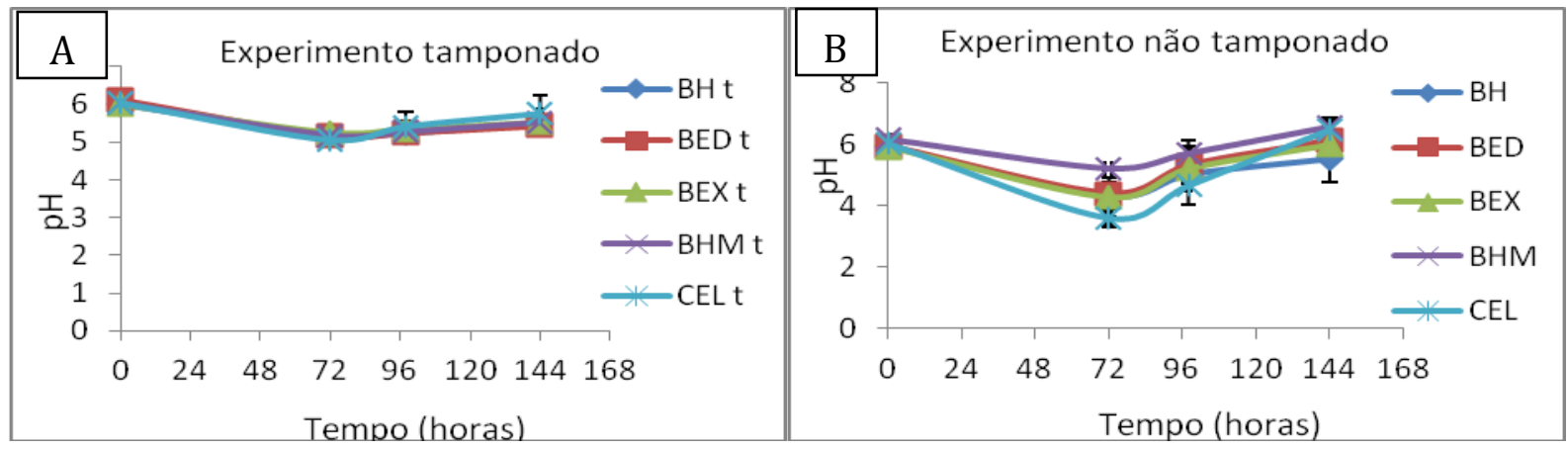

Figura 2: Variação do $\mathrm{pH}$ ao longo do cultivo do fungo $P$. echinulatum S01M29 em fermentação submersa com as diferentes fontes de carbonos. Média das triplicatas com seu respectivo desvio padrão. A) Com pH 5,9 controlado pelo tampão biftalato de potássio 0,1M. B) pH livre, sem nem um controle.

\section{- Para o fungo Filamentoso Trichoderma harzianum linhagem P49P11}

A Figura 3 mostra a atividade de Fpase e a variação do $\mathrm{pH}$ ao longo tempo do cultivo na presença e na ausência do controle do $\mathrm{pH}$ pelo tampão ftalato de potássio $0,1 \mathrm{M} \mathrm{pH} 5$. Como pode ser observado o controle de $\mathrm{pH}$ para a atividade de Fpase nos diferentes meios de cultivos contribuiu para a diminuição do desvio padrão entre as triplicatas e padronizou a atividade de Fpase, sendo observado o mesmo para o Penicillium echinulatim PS1M29.
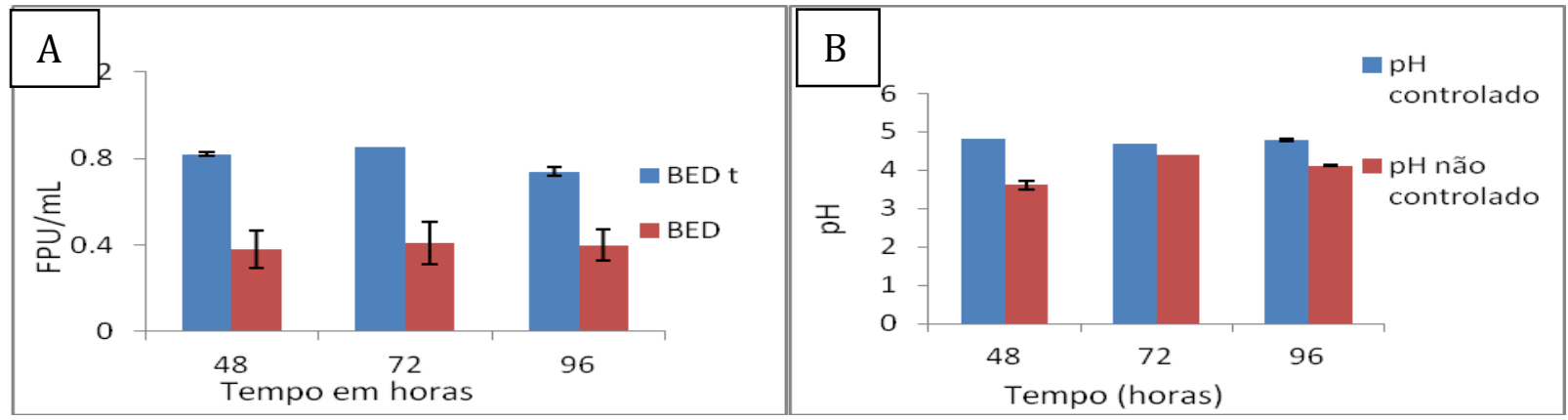

Figura 3: A) Cinética da produção de Fpase pelo fungo Trichoderma harzianum em fermentação submersa com as diferentes fontes de carbonos com pH 5,5 controlado pelo tampão biftalato de potássio $0,1 \mathrm{M}$ e pH livre, sem nem um controle. Média das triplicatas com seu respectivo desvio 
padrão. B) Variação do $\mathrm{pH}$ ao longo do cultivo do fungo Trichoderma harzianum em fermentação submersa com as diferentes fontes de carbonos com pH 5,5 controlado pelo tampão biftalato de potássio $0,1 \mathrm{M}$ e $\mathrm{pH}$ livre, sem nem um controle. Média das triplicatas dos ensaios com seu respectivo desvio padrão.

\subsection{Aplicação do controle do pH pelo ftalato de potássio $0,1 \mathrm{M}$ em planejamentos estatísticos de otimização/modulação de meios de cultura em frascos agitados}

\section{- Para o fungo filamentoso Penicillium echinulatim PS1M29}

Observa-se que o tampão biftalato de potássio estabilizou o $\mathrm{pH}$ para todos os ensaios do planejamento nos diferentes tempos de cultivo (Figura 4). Costa (2012a), através desse planejamento, modulou e otimizou meios de cultura para as atividades das glicohidroláses. A eficiência do método abre um grande leque de possibilidade de estudos sobre os indutores que atuam em conjunto ou individualmente na expressão de glicohidroláses em cultivos submersos.

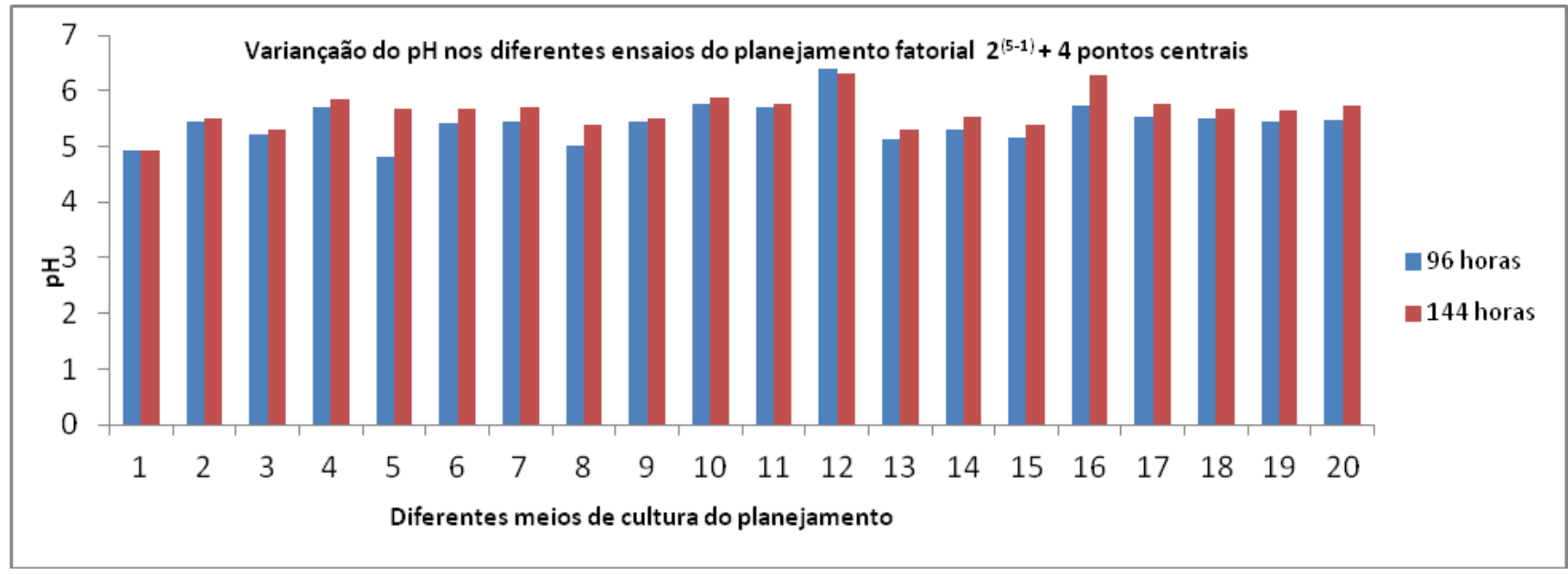

Figura 4: Variação do pH ao longo dos ensaios de cultivo do fungo P. echinulatum S01M29 em planejamento estatístico fracionado para verificação da influência de cinco componentes do meio de cultura.

\section{- Para o fungo Filamentoso Trichoderma harzianum linhagem P49P11}

Observa-se que o tampão biftalato de potássio estabilizou o $\mathrm{pH}$ para todos os ensaios do planejamento nos diferentes tempos de cultivo (Figura 5). Percebe-se um eficiente controle do $\mathrm{pH}$ para todos os ensaios do planejamento, mostrando a potencialidade do uso desse tipo de controle de $\mathrm{pH}$ para otimizações de meios de cultura em menor escala. O uso desta técnica para otimizações iniciais de meio de cultura permite um amplo estudo de indutores das glicohidrolases. 


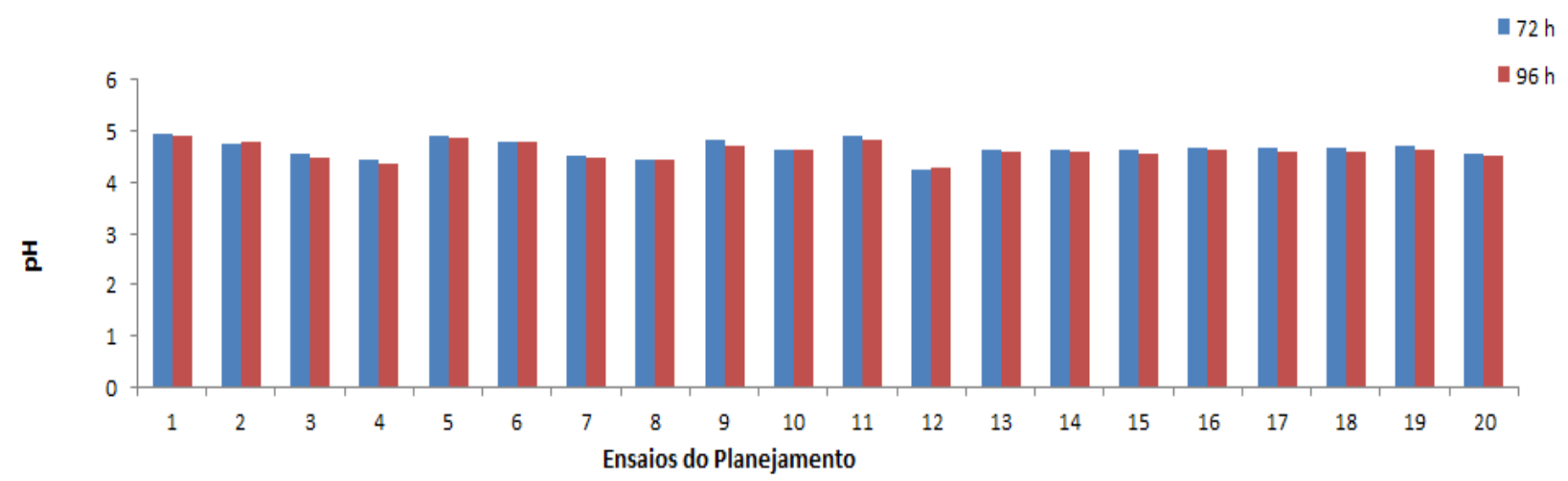

Figura 5: Variação do $\mathrm{pH}$ ao longo dos ensaios de cultivo do fungo Trichoderma harzianum para planejamentos estatísticos do tipo completo rotacional (DCCR) para verificação da influência de tres componentes do meio de cultura.

\section{CONCLUSÃO}

Com base nesse trabalho pode-se afirmar que o controle do $\mathrm{pH}$ pelo tampão ftalato de potássio para os fungos filamentosos $P$. echinulatum S01M29 e Trichoderma harzianum foi eficiente no decorrer dos cultivos.

A presença do tampão no meio de fermentação obteve uma influência positiva para a atividade de Fpase para os dois fungos em estudo.

A aplicação do controle do $\mathrm{pH}$ pelo tampão biftalato de potássio foi eficiente em experimentos de modulação e otimização de meios de culturas para os fungos filamentosos $P$. echinulatum S01M29 e Trichoderma harzianum respectivamente. Essa técnica pode se expandir para demais fungos filamentosos no intuito de incrementar a produção de glicohidroláses por componentes do meio de cultura em uma escala menor de trabalho e com maiores possibilidades de estudar uma grande quantidade de indutores em conjunto.

\section{REFERÊNCIAS}

COSTA PS, DELABONA PS, ROLB D, DILLON AJP, PRADELLA JGC. Modulação da produção de celulases em Penicillium echinuatum PS1M29 pela variação dos componentes do meio de cultura. X Seminário Brasileiro de Tecnologia Enzimática. 7 a 10 de Outubro, Blumenau, Santa Catarina, Brasil. 2012b

DELABONA PS, FARINAS CS, SILVA MR, AZZONI SF, PRADELLA, JGC. Use of a new Trichoderma harzianum strain isolated from the Amazon rainforest with pretreated sugar cane bagasse for on-site cellulase production. Bioresour Technol 107: 517-521, 2012a. 
DOMINGUES, F.C.; QUEIROZ, J.A.; CABRAL, J.M.S.; FONSECA, L.P. The influence of culture conditions on mycelial structure and cellulose production by Trichoderma reesei Rut C30. Enzyme and Microbial Technology. 26: 394-401, 2000.

MANDELS, M.; REESE, E. T. Induction of cellulase in Trichoderma viride as influenced by carbon sources and metals. The Journal of Bacteriology, v. 73(2), p. 269-278, 1957.

STERNBERG, D.; DORVAL, S. Cellulase production and ammonia metabolism Trichoderma reesei on high levels of cellulose. Biotechnology and Bioengineering 21, 181-191, 1979.

TANGNU, S.K.; BLANCH, H.W.; WILKE, C.R. Enhanced production of cellulase, hemicellulase and $\beta$-glucosidase by Trichoderma reesei (RUT C-30). Biotechnology and Bioengineering, 23, 1837-1849, 1981. 